\title{
Informática na Educação baseada em Evidências: Um Manifesto
}

\author{
Evidence-based Computers in Education: A Manifesto
}

\section{Ig Ibert Bittencourt}

Núcleo de Excelência em Tecnologias Sociais - NEES

Universidade Federal de Alagoas

ig.ibert@ic.ufal.br

\author{
Seiji Isotani \\ Laboratório de Computação Aplicada à Educação \\ ICMC - Universidade de São Paulo \\ sisotani@icmc.usp.br
}

\section{Resumo}

Este manifesto nasceu devido a um processo de auto-reflexão, busca de melhoria contínua do sujeito-pesquisador e do constante impulso que nos move a compartilhar com a comunidade nossas impressões, sejam elas dolorosas ou não, para nós e para outros. Desta forma, trazemos à luz a evidência e a reprodutividade da pesquisa como fatores fundamentais para a melhoria da qualidade das pesquisas que estão sendo negligenciados pela comunidade de Informática na Educação. Com isso, elencamos dez princípios baseados em nossas observações e vivências ao longo dos últimos quinze anos de interação com a comunidade científica interessada em produzir conhecimento, produtos e inovação nesta área estratégica para o desenvolvimento social e econômico do país. Apresenta-se aqui uma carta aberta para o estímulo ao debate e a provocação ao movimento pela pesquisa em Informática na Educação baseada em evidências.

Palavras-Chave: Manifesto, Educação baseada em Evidências, Informática na Educação

Cite as: Bittencourt, I. I. \& Isotani, S. (2018). Evidence-based Computers in Education: A Manifesto (Informática na Educação baseada em Evidências: Um Manifesto). Brazilian Journal of Computers in Education (Revista Brasileira de Informática na Educação - RBIE), 26(3), 108-119. DOI: 


\section{Introdução}

Em 2017, a Revista Brasileira de Informática na Educação (RBIE) fez 20 anos, mas as pesquisas em informática na educação começaram a ser realizadas no Brasil muito antes disso. Como bem apresenta o artigo do Prof. José A. Valente, publicado na primeira edição da RBIE em 1997, as pesquisas realizadas nesta área no Brasil são datadas da década de 70 (Valente, 1997). Em quatro décadas, a comunidade cresceu de algumas dezenas de pesquisadores, isolados em centros de pesquisas de excelência, para quase 3 mil pesquisadores espalhados em todo o território brasileiro, de acordo com a lista de discussão da SBC-IE. Essa evolução é decorrente de uma característica inerente da comunidade de agregar e recepcionar de braços abertos novos pesquisadores de diferentes áreas do conhecimento, sem exceção. Utilizando-se das palavras do nosso saudoso colega Professor Dr. Alexandre Direne, podemos dizer que "a comunidade de Informática na Educação é uma das mais democráticas na área de Computação do Brasil”".

Essa característica traz diversos benefícios para apoiar os processos de ensinoaprendizagem, pois é possível atacar um mesmo problema utilizando diferentes perspectivas e abordagens provindas de áreas de conhecimento distintas. Dessa forma, o ambiente de pesquisa torna-se um local rico e propício para realizar trabalhos multidisciplinares onde pesquisadores de diferentes áreas se utilizam de diferentes métodos para identificar as melhores formas de solucionar problemas educacionais de maneira integrada e com resultados potencialmente mais robustos.

Entretanto, apesar da caracterização democrática da comunidade, ainda são poucas as pesquisas de excelência e de nível internacional desenvolvidas pela nossa comunidade. Há um número reduzido de pesquisadores convidados como palestrantes principais (keynote speakers) ou que façam parte de comitês de programa de eventos de alto nível internacional, o que mostra ainda a pouca expressividade da comunidade no cenário mundial ${ }^{1}$. Correlacionado a este fato, poucos pesquisadores da comunidade possuem expressivo número de citações, seja no Web of Science, Scopus ou no Google Citations.

São vários os potenciais fatores que podem ter levado a comunidade, ao longo das quatro décadas de pesquisa em Informática na Educação no Brasil, a possuir baixo nível de excelência/impacto nas pesquisas desenvolvidas. Alguns exemplos que podemos citar são: poucas oportunidades de fomento de pesquisa para a área; poucos programas de pós-graduação em Informática na Educação; barreira da língua inglesa; baixa interação com agentes do ecossistema de tecnologia educacional do país; êxodo de pesquisadores de alto nível para outras áreas da computação, educação e afins; falta de envolvimento de pesquisadores renomados em eventos da comunidade; pesquisadores considerarem a informática na educação como sua área de pesquisa secundária ou terciária; pouca colaboração entre os pesquisadores da área, dentre outros. Ou seja, são muitos os fatores que podem ter levado a área a ter, até o momento, baixa expressividade no Brasil e no exterior. Contudo, essas dificuldades não podem ser impedimento para que a comunidade se desenvolva mais rapidamente nas próximas décadas.

Dessa forma, trazemos à luz dois fatores que consideramos fundamentais para a melhoria da qualidade das pesquisas que estão sendo negligenciados pela comunidade de Informática na Educação. São eles: a evidência e a reprodutividade da pesquisa. Em pesquisas realizadas por Magalhães et al. (2013), são poucos os trabalhos publicados no SBIE, WIE e RBIE que apresentam evidências científicas que sustentem as proposições feitas. Por exemplo, O SBIE possui aproximadamente $90 \%$ dos seus trabalhos sem nenhum tipo de evidência científica (sejam elas de pesquisas quantitativas, qualitativas ou mistas), enquanto que eventos como o

\footnotetext{
${ }^{1}$ Esta visão dos autores pode ser corroborada ao analisar os nomes dos pesquisadores de maior expressividade na comunidade (Posada et al., 2016) e suas respectivas contribuições também no cenário internacional.
} 
International Conference on Artificial Intelligence in Education apresentam em torno de 90\% de evidências científicas em seus artigos (Blanchard, 2015). Sem evidências não há reprodutibilidade das pesquisas, pois não há como comparar resultados e verificar se os métodos aplicados para alcançar tais resultados são, de fato, adequados. Por exemplo, se um pesquisador diz que uma abordagem pedagógica $\mathrm{X}$ aumenta a performance dos alunos em $\mathrm{Y} \%$, é fundamental que um outro pesquisador consiga utilizar a mesma abordagem $\mathrm{X}$ com um outro grupo de alunos e encontrar valor igual ou similar a Y\%. Essa reprodução de resultados é essencial para o progresso científico e para a construção incremental do conhecimento. É importante frisar que esta reprodutividade não se limita, exclusivamente, à replicação de experimentos controlados, mas também ao desenvolvimento de pesquisas qualitativas que constroem e articulam novos conhecimentos sob a égide de outras pesquisas baseadas em evidências.

É importante frisar que movimentos como este, almejado neste artigo, já foram conduzidos por diferentes grupos, entidades e comunidades (e.g. http://www.cieb.net.br/evidencias/, $\quad$ https://educationendowmentfoundation.org.uk/ $\quad \mathrm{e}$ https://ies.ed.gov/ncee/wwc/). Tais movimentos podem levar a uma ruptura na forma de atuação dessas comunidades e consequente redirecionamento de ações que levaram ao aumento da qualidade ao alcançar os objetivos traçados (Benassi et al. 2014). Desta forma, este documento tem por objetivo fazer um chamamento e provocação à comunidade por uma Informática na Educação baseada em Evidências, e com isso, apresentar um manifesto com princípios que consideramos importantes a serem trabalhados.

\section{Princípios}

São apresentados aqui dez princípios baseados em nossas observações e vivência ao longo dos últimos quinze anos de interação na comunidade de Informática na Educação (IE). É importante deixar claro que os princípios não têm por objetivo serem excludentes ao propor um enfoque dos pesquisadores em detrimento a outro. Por exemplo, sem dúvida propostas teóricas próprias ou questionários próprios são relevantes e importantes para a comunidade, entretanto tais proposições sem clareza conceitual ou validação do instrumento são inexpressivos e inadequados sob um ponto de vista científico. Destaca-se ainda que novos princípios podem ser adicionados e os princípios apresentados foram sumarizados para que tal extrapolamento não leve a uma perda de foco das pesquisas baseadas em evidência. Outro ponto importante é que os princípios não se limitam ao paradigma de evidências, mas também objetiva apresentar princípios intermediários e secundários, porém fundamentais para tal paradigma.

\subsection{Princípio I: Menos monólogo, mais diálogo}

Dialogar e trocar experiências são comportamentos fundamentais para a boa formação do pesquisador, para o desenvolvimento de uma pesquisa mais robusta e para o fortalecimento da comunidade (Pyrko et al., 2017). Infelizmente, temos observado um enfraquecimento deste comportamento na comunidade brasileira. É difícil encontrar no CBIE (e em outros eventos brasileiros) debates acalorados entre pesquisadores que estudam um mesmo tema e têm visões diferentes, mas que se respeitam mutuamente. Ou seja, estamos numa situação onde existe um monólogo: "Eu faço minha pesquisa aqui no meu laboratório e você faz a sua aí no seu laboratório; sem contestação, sem troca de experiências". Esse comportamento é extremamente nocivo para a comunidade e está corroendo a oportunidade que temos de fazer pesquisas de relevância para melhorar a educação do país e do mundo.

Para que esse diálogo ocorra de forma coerente e racional, é imprescindível que existam dados disponíveis para que a troca de experiências ocorra no campo das evidências e não das 
suposições. Como cientistas, não é saudável que nos deixemos cair em tentação utilizando um discurso baseado em achismo (i.e. "eu acho isso, você acha aquilo, mas de fato não sabemos de nada"). A exemplo disto, podemos citar um comentário feito por uma colega para um palestrante durante o CBIE de 2017: "já existem muitos resultados empíricos na literatura que indicam que esse tipo de pesquisa não oferece beneficios à aprendizagem; então qual o objetivo de você utilizar essa abordagem? Qual a relevância do seu trabalho?". Para alguns pode parecer um comentário rude; para outros um ataque à própria pessoa que fez a apresentação. Contudo, para efeitos científicos, esse comentário é de suma importância por dois motivos: primeiro, evita que conceitos errôneos se propaguem na comunidade; segundo, tem um efeito didático de curto-médio prazo fazendo com que as pessoas envolvidas reflitam mais sobre seus trabalhos, preparem-se mais (ou seja, leiam mais trabalhos relacionados considerando múltiplas perspectivas) e, finalmente, escrevam e apresentem artigos mais bem embasados, justificados e fundamentados.

O que queremos esclarecer com este princípio é que fazer críticas construtivas e colaborar com outros pesquisadores é fundamental para a realização de pesquisas de qualidade (Liao, 2010), bem como para o crescimento do cientista e da própria comunidade. Um palestrante, ao apresentar um trabalho, não deve esperar apenas um elogio, mas sim perguntas intrigantes, e às vezes desafiadoras, que o façam repensar sobre suas próprias práticas científicas. Em contrapartida, as pessoas da plateia não devem escutar de maneira passiva. É preciso ser ativo, pensar sobre o trabalho apresentado e atuar como auditores que querem contribuir para a melhoria da pesquisa do palestrante. Sem essa interação, para que então participar de nossas conferências? Só pra ter mais uma linha no currículo lattes e conhecer mais um lugar-?

Precisamos sair desta zona de conforto que criamos e implodir as bolhas de pensamento fragmentadas nas quais nos alojamentos. É preciso que a comunidade aprenda a escutar críticas e também a fazer críticas construtivas utilizando como ponto de debate as hipóteses formuladas, os métodos e materiais desenvolvidos/utilizados, as evidências encontradas e as contribuições obtidas. É preciso criar nossa própria comunidade de prática! Sem ela continuaremos a trabalhar sozinhos, sem rumo, sem perspectiva, sem melhoria.

Um exercício, que você leitor, pode fazer relacionado a este princípio, é continuar a leitura deste texto com a mente aberta, pronto para o debate, e entender que estamos fazendo uma crítica e autocrítica construtivas. Ou seja, não nos abstemos dos erros que cometemos e, esperamos que, com o debate sobre esses princípios, possamos crescer conjuntamente.

\subsection{Princípio II: Menos estudos independentes, mais estudos fundamentados no estado da arte}

Para fundamentar esse princípio, vamos the fazer duas perguntas: (1) Quem são os pesquisadores ou grupos de pesquisa mais importantes em sua grande área de atuação que têm destaque no Brasil? E no exterior? (2) Quais são os desafios e questões de pesquisa mais relevantes da sua área de atuação? Se você respondeu essas duas perguntas facilmente então você merece aplausos e congratulações.

O que vemos atualmente é que poucos pesquisadores ou pesquisadores em formação (i.e. alunos de iniciação científica, mestrado e doutorado) conhecem o estado da arte em sua área de pesquisa e, tampouco, conhecem quem são os pesquisadores ícones nestas áreas. Por exemplo, há 15 anos se perguntássemos qual era o grupo de pesquisa mais relevante na área de CSCL (Computer-Supported Collaborative Learning) no Brasil, rapidamente viria à mente o grupo do Prof. Hugo Fuks da PUC-RIO e seus trabalhos com o AulaNet, modelo 3C e Engenharia de Groupware (Fuks et al., 2002). A mesma pergunta poderia ser feita para a área de Inteligência Artificial aplicada na Educação. Facilmente, as pessoas indicariam o grupo da Profa. Rosa 
Maria Vicari da UFRGS e seus trabalhos com sistemas tutores inteligentes, padrão OBAA ${ }^{2}$, multiagentes e modelo BDI (Vicari et al., 2003).

Ao iniciar uma pesquisa, muitos deixam de fazer o dever de casa, ou seja, fazer um estudo aprofundado do estado da arte por meio de uma revisão da literatura. Contudo, é a partir deste estudo aprofundado que é possível entender os problemas de pesquisa mais atuais e relevantes que podem contribuir com a área e a comunidade. Infelizmente, por meio de nossa participação ativa nos comitês organizadores e de programa dos eventos da Comissão Especial de Informática na Educação (CEIE), observamos que a maioria das submissões carece de uma seção de trabalhos relacionados. Além disso, muitos confundem fundamentação teórica com trabalhos relacionados, e como consequência, grande parte dos trabalhos conduzidos por nossa comunidade são realizados por comodidade ou conveniência com pouco comprometimento científico em enriquecer e aprofundar o conhecimento da área. Ou seja, são estudos independentes que, apesar de potencialmente interessantes, não auxiliam a área a construir incrementalmente (ou até disruptivamente) seus conhecimentos e a resolver seus grandes desafios.

Isso significa que se continuarmos com essa prática, se passarão mais 20 anos e estaremos falando das mesmas coisas, tentando lidar com os mesmos problemas e, por fim, nos perguntando sobre o porquê de nossas pesquisas não chegarem a proporcionar impacto relevante nas escolas e nas políticas públicas em educação do país.

\subsection{Princípio III: Menos teorias avulsas, mais compromisso ontológico e epistemológico}

Observamos na comunidade muitas propostas de teorias avulsas, com baixo fundamento científico e sem consonância com o estado da arte da área. Falta de clareza de fundamento teórico se dá, principalmente, pela falta de compromisso ontológico e epistemológico do pesquisador. Ou seja, não há uma reflexão dos pesquisadores da comunidade sobre como o mesmo concebe a realidade das coisas (dimensão ontológica) e como o conhecimento é construído com base nesta realidade (dimensão epistemológica). Acrescentam-se a estas dimensões, as dimensões metodológica, ética e política da pesquisa científica. Isto faz com que muitos pesquisadores fiquem em processo de autofagia onde sua "sobrevivência acadêmica" depende da construção de conhecimento em cima de teorias avulsas.

Sendo assim, o efeito colateral que se tem com a vacuidade das fundações referentes às dimensões do conhecimento são artigos pseudocientíficos que apresentam teorias avulsas e conceitualmente inconsistentes, tentativas de fusão de diferentes propostas teóricas que se contradizem em suas dimensões ontológicas e/ou epistemológicas, oscilação de pesquisas de um mesmo pesquisador trafegando em diferentes dimensões, entre outros. Mais uma vez destacamos que não estamos nos eximindo deste problema e já choramos juntos com a comunidade deste mal. Joguem fora muitos de nossos artigos!!!

É difícil rastrear e encontrar a raiz deste problema, mas é evidente que a natureza inerentemente interdisciplinar da Informática na Educação torna o problema mais complexo. A pesquisa na área se relaciona com Ciência da Computação, Engenharia, Pedagogia, Psicologia, Sociologia, Antropologia, Filosofia, Neurociência, dentre outras. Além disso, a área considera diferentes dimensões do sujeito (seja ele aluno, professor, gestor, pais), como física, psicológica, fisiológica, ética, política, interacional, dentre outras.

Alguns encaminhamentos de solução que já são percebidos pela comunidade são as iniciativas da Comissão Especial de Informática na Educação sobre a formação básica do pesquisador, através da produção de livros sobre a área (Jaques et al., 2017; Jaques et al., 2018); artigos recentemente publicados em primeira pessoa pelo pesquisador Mariano Pimentel da

\footnotetext{
2 http://www.portalobaa.org/
} 
UNIRIO (Pimentel, 2018) que define seus fundamentos onto-epistemológicos; e pesquisas lideradas pela Professora Cecília Baranauskas da UNICAMP sobre sistemas sócio-enativos, que não só possuem robustez conceitual, mas avançam a ciência em busca de uma nova epistemologia.

Talvez ainda seja preciso que a comunidade reflita, rastreie e compreenda que o percurso teórico fundacional e não linear da área parte dos filósofos e matemáticos antigos, passando pela razão moderna cartesiana, a empiria de Locke, as tentativas de fusão científica de Cristiam Wolff e Immanuel Kant, os vetos kantianos, o positivismo comtiano, o relativismo cultural de Franz Boas, a escola interpretativista, o empirismo lógico do Círculo de Viena, a epistemologia genética piagetiana, o funcionalismo/pragmatismo americano, o construcionismo de papert, o behaviorismo de Watson e Skinner, o sócio-construtivismo de Vygotsky, a pedagogia freiriana, o cognitivismo presente na inteligência artificial, os paradigmas de Kuhn, a falseabilidade de Popper, o pós-positivismo, o pós-estruturalismo foucaultiano, as epistemologias das pesquisas mistas, o empiricismo construcionista de Von Fraise, dentre outros.

\subsection{Princípio IV: Menos propostas conceituais, mais validação científica}

É muito comum se observar em artigos da comunidade, principalmente no Simpósio Brasileiro de Informática na Educação, propostas de uma arquitetura de software, a aplicação de uma técnica de inteligência artificial, uma proposta de ontologia ou mapa conceitual, mais recentemente o uso de gamificação, computação afetiva, IoT, dentre outros, porém sem nenhuma tentativa de validação daquela proposta conceitual. Conforme já demonstrado por Magalhães et al. (2013), este fato está presente não somente em artigos curtos, mas também em artigos completos que ainda costumam ser aprovados pela comunidade.

O efeito colateral disto é um processo de salame science (Huth, 1986), onde os pesquisadores submetem artigos à medida que geram seus artefatos educacionais. Como resultado, produzimos maus exemplos para jovens pesquisadores ao acreditarem em determinado tipo de ciência e uma má reputação da comunidade perante áreas de pesquisa mais robustas, o que impacta na descentralização de fomento de pesquisa para a comunidade, gerando assim um ciclo vicioso em torno de pesquisa de má qualidade ou pseudo-ciência. Obviamente há muitos pesquisadores sérios da comunidade, que buscam publicar seus trabalhos de forma embasada e metodologicamente consistente. Entretanto, caso você, leitor e pesquisador, se identifique e talvez se irrite com o que está escrito neste princípio, pode ser um excelente momento de rever a sua prática científica e exercitar os Princípios I, II e III.

Há várias razões que levam a este tipo de atitude, como o sistema nacional de avaliação de pesquisadores focado na quantidade, a ansiedade do pesquisador em ter seus trabalhos reconhecidos, a busca pela corrida da bolsa de produtividade ou outros incentivos de financiamento de pesquisa, a ridícula e insana competição entre pesquisadores dentro dos departamentos e institutos universitários, dentre outros.

$\mathrm{Na}$ contra-mão deste tipo de atitude, há pesquisadores que vêm desenvolvendo suas pesquisas consistentemente, seguindo o ritual esperado para uma produção científica de qualidade, como o Professor Paulo Blikstein da Universidade de Stanford e suas pesquisas sob um paradigma construcionista (Blickstein, 2013a) e sobre análise da aprendizagem multimodal (Blickstein, 2013b). Podemos citar também as pesquisas da Professora Patrícia Jaques da UNISINOS e sua pesquisa com o PAT2Math - http://pat2math.unisinos.br/ (Jaques et al., 2013).

Caminhos de solução para este problema passam inevitavelmente pela formação básica de pesquisadores e pela conscientização de pesquisadores seniores de que precisam melhorar suas práticas. Além disso, talvez seja o momento de levarmos menos a sério (ou ignorarmos) os mecanismos de avaliação científica nacional e passarmos a fazer pesquisa com mais rigor, que sigam os passos necessários à sua realização. 


\subsection{Princípio V: Menos questionários próprios, mais instrumentos validados}

Outro problema que se mostra também recorrente na comunidade é o desenvolvimento de pesquisas que buscam suas validades através de questionários desenvolvidos pelos próprios pesquisadores, porém sem nenhum rigor. $O$ que mais se observa são questionários que basicamente perguntam ao usuário se eles gostaram do uso e se o sistema está adequado às suas necessidades. Entretanto, tais questionários, comumente, não foram construídos considerando técnicas de ameaça à validade, nem validados para a comunidade brasileira (Pasquali, 2017).

O efeito colateral disto são artigos sendo publicados com pseudo-avaliações de tecnologias educacionais que não auxiliam na construção do conhecimento de determinada área, contendo aplicação de questionários com membros do próprio grupo de pesquisa ou pessoas conhecidas ou com traduções de questionários validados para outra língua e cultura, dentre outros. Mais uma vez, joguem fora outra dezena de artigos nossos!

Estes problemas conceituais, presentes nos pesquisadores da comunidade de IE (mas não restrito a ela), são devido à falta de formação sobre métodos de pesquisa para a área. Obviamente que este gap é amplificado devido aos problemas citados nos princípios anteriores, como por exemplo o princípio III, pois a dimensão do conhecimento metodológico possui uma relação de subserviência com as dimensões ontológicas e epistemológicas. Frisa-se ainda que métodos e técnicas de pesquisa a serem aplicados dependem da relação com outras disciplinas e com a dimensão do sujeito que estamos considerando em nossas pesquisas.

Algumas iniciativas que caminham nesta direção são: a iniciativa da CEIE em produzir livros sobre metodologia da pesquisa em IE; as pesquisas desenvolvidas por pesquisadores brasileiros que começam a validar instrumentos; a aplicação de instrumentos validados por psicometristas para o contexto brasileiro; o aumento do incentivo a pesquisadores de Informática na Educação submeterem suas pesquisas para aprovação pelo Comitê de Ética; a aplicação de outros instrumentos de coleta e medição de dados como eletroencefalograma, biosensores, log de sistema, dentre outros.

Mais uma vez, ainda se faz necessária a formação sobre metodologias e métodos de pesquisa em Informática na Educação, mas principalmente a construção de protocolos que tenham o objetivo de avaliar um construto específico. Estas iniciativas são muito comuns na Medicina baseada em Evidências (MBE) e na Psicologia Experimental, onde a observação de determinado construto deve seguir obrigatoriamente um protocolo (que também já foi exaustivamente investigado) para que ele possa ser considerado válido.

\subsection{Princípio VI: Menos purismo acadêmico, mais interface com o ecossistema educacional}

Um desafio estrutural e organizacional que qualquer pesquisador ou grupo de pesquisa enfrenta é fazer com que suas pesquisas cheguem ao público alvo de interesse (e.g. estudantes, professores, pais, gestores), bem como alcancem atores do ecossistema educacional (e.g. secretarias, redes de ensino, escolas, universidades, empresas, investidores, ONGs) de forma significativa. O que se observa é que há $(i)$ um distanciamento entre o que a academia está pesquisando e uma demanda do ecossistema educacional; (ii) incapacidade dos pesquisadores e incubadoras em traduzir uma pesquisa de relevância científica em um modelo de intervenção educacional que gere impacto positivo e significativo na educação e em políticas públicas e (iii) falta de profundidade da pesquisa em resolver o problema educacional que está posto.

Como consequência desta precária interação dos pesquisadores da área com os atores do ecossistema educacional emerge uma descrença na pesquisa nacional e na capacidade dos pesquisadores em apoiar na resolução de problemas educacionais complexos e relevantes. Com isso, poucos pesquisadores da área atuam em colaboração com o Ministério da Educação, 
Conselhos Estaduais e Municipais de Educação, empreendedores, Organizações sem fins lucrativos e a sua própria universidade no estabelecimento de políticas públicas educacionais de alto impacto.

Rastrear este problema não é simples, mas com certeza é um problema histórico da pesquisa científica nacional, independente da área de Informática na Educação, onde era considerado suficiente que os pesquisadores ficassem apenas em seus laboratórios de pesquisa e publicando artigos nos fóruns de suas respectivas áreas. Mas, para você leitor, o que é mais relevante: publicar 10 artigos em periódicos e conferências da área ou fazer com que sua pesquisa auxilie 10 estudantes a escolherem sua carreira, a desenvolver competências para a vida adequadamente ou aprová-los no ENEM numa universidade pública? Se formos pensar na contribuição cientifica per capita de nossas pesquisas (i.e. a relação entre trabalhos publicados e impacto gerado ao público alvo), qual seria sua resposta?

Iniciativas que vão na contra-mão do purismo acadêmico podem ser observadas em todas as regiões do país. Destacamos aqui os trabalhos sendo desenvolvidos pelo LITE Laboratório de Inovação Tecnológica na Educação (http://ite.acad.univali.br/), sob a Coordenação do Professor André Raabe, da Univale. O LITE tem desenvolvido vários trabalhos em cooperação com escolas e estudantes da educação básica e participado de iniciativas fora dos eventos científicos, como a Campus Party e ações da Fundação Lemann. Outra iniciativa pode também ser observada pela Universidade Federal do Ceará, com os pesquisadores Mauro Pequeno e José Aires de Castro Filho que atuam em cooperação com o Ministério da Educação (MEC) no estabelecimento de diferentes políticas educacionais, tanto para o ensino superior quanto para a educação básica. Entretanto, ainda há poucos pesquisadores que possuem este nível de interação.

Desta forma, há a necessidade de um premente estímulo à aproximação dos diferentes stakeholders do ecossistema educacional. Não existe solução rápida e fácil, mas um passo importante está tanto na participação dos pesquisadores em encontros educacionais não científicos, quanto na integração de outros atores nos eventos da comunidade. Ou seja, a comunidade precisa se expor mais, ouvir, ser ouvida, refletir e buscar caminhos de interação qualitativa e duradoura.

\subsection{Princípio VII: Menos descontinuidade, mais foco em objetivos de longo prazo}

Um grande problema na nossa comunidade é a dificuldade de desenvolver pesquisas que tenham impacto a longo prazo. Veja que este é um problema não só da nossa comunidade, mas se estende a computação, pedagogia, psicologia educacional e outras áreas. O que mais se observa é a descontinuidade e a falta de foco das pesquisas da área, onde os pesquisadores desenvolvem suas pesquisas sem direcionamento. Ou seja, definem suas pesquisas de acordo com o interesse de um novo aluno, possibilidade de cooperação com um pesquisador internacional (i.e. atuando nas pesquisas do pesquisador internacional) e até mesmo devido aos hypes da área, como os estilos de aprendizagem, gamificação, mineração de dados educacionais, e os novos hypes IoT na Educação e Computação Afetiva.

Como resultado desta descontinuidade, as pesquisas da área são rasas, com baixa relevância científica, que leva a poucas citações e os resultados são publicados em revistas domésticas, conferências caseiras ou em livros organizados por pesquisadores do próprio círculo de interação. O problema fica ainda mais acentuado pelo mito do qualis, que leva pesquisadores (principalmente mestrandos, doutorandos e recém-doutores) a acreditarem que a publicação da forma supracitada valida uma pesquisa de qualidade. Fazer pesquisa leva tempo. É preciso uma década para construir um portfólio sólido em uma linha de pesquisa.

São várias as razões que levam a este tipo de problema, mas sem dúvida a falta de uma formação teórica na área de Informática na Educação é um dos pivôs. Esta carência é, muitas 
vezes, resultante da incompreensão dos estudantes sobre o estado da arte e da prática e em não entender quais são os problemas relevantes ou grandes desafios da área. Como historicamente a área nunca teve uma formação robusta, muitos doutores da área sofrem do mesmo problema, que limita a capacidade de gerar um curso de formação de qualidade e, com isso, o problema é basicamente retroalimentado ao longo do tempo e das novas gerações. Aliado a isto, muitos pesquisadores não acreditam que possuem esta limitação ou não estão dispostos a superar tal limitação.

É difícil encontrar pesquisas que de fato possuam uma continuidade e que sejam trabalhadas com objetivos claros sendo maturados e avaliados ao longo do tempo. Por exemplo, não é de nosso conhecimento estudos longitudinais desenvolvidos na IE. Talvez seja por isso que estejamos reinventendo a roda em ciclos decenais, que tem nos levado ao abismo da tentativa de resolução dos mesmos problemas nos 40 anos que temos de pesquisa nacional em IE. Uma evidência disto é a palestra dada pelo professor José Armando Valente, no CBIE 2014 (em Dourados - MS), sobre os problemas de pesquisa em IE atuais. Nessa palestra, o mesmo trouxe suas transparências de uma palestra dada na década de 80 do século passado, que foram exibidas num ultrapassado retroprojetor. Curiosamente, os desafios atuais apresentados por muitos pesquisadores são os mesmos que ele apresentou na época. Assim, perguntamos a você, leitor, será que estamos caminhando em círculos? Será que nossas pesquisas são de longo prazo (e.g. 10 anos) ou estamos buscando o próximo artigo de revista?

\subsection{Princípio VIII: Menos pesquisas de caixa-preta, mais abertura de dados}

É de suma importância a realização de pesquisas onde os dados, métodos, instrumentos e resultados são compartilhados e disponibilizados para que seja possível não somente replicar os estudos, mas também dar melhor compreensão e objetividade à pesquisa que está sendo desenvolvida. Isso permite que tanto o pesquisador quanto outras pessoas da comunidade possam construir/descobrir novos conhecimentos baseados em resultados anteriormente obtidos.

Assim, abrir a caixa-preta de nossas pesquisas e disponibilizar os dados coletados de forma aberta e transparente poderá agilizar o compartilhamento de conhecimento e, dessa forma, o amadurecimento e fortalecimento da comunidade em Informática na Educação com base nas evidências produzidas. O mesmo vale para todos os produtos/artefatos (software, hardware, processos, frameworks, etc) que desenvolvemos.

Imagine o grande avanço das pesquisas se as ferramentas produzidas pela comunidade não fossem descontinuadas e estivessem disponíveis e em desenvolvimento por 20 ou 30 anos por diferentes grupos de pesquisa? Imagine que os dados dessas ferramentas estivessem todos disponíveis como dados abertos conectados (Isotani \& Bittencourt, 2015)? Acreditamos que nossa comunidade estaria na fronteira do conhecimento e da inovação na área de mineração de dados educacionais já que temos milhares de dados que poderiam ser potencialmente analisados (e.g. dados de alunos que cursam graduação e/ou pós-graduação nas universidades brasileiras na forma de EAD). Imagine os potenciais ganhos para educação brasileira se esses dados pudessem ser integrados e estudados? Seria possível melhorar a distribuição de recursos, reduzir gastos desnecessários, dar agilidade nos processos administrativos, e assim por diante.

Esse cenário só será possível quando tivermos a coragem de abrir todos os dados de nossas pesquisas para que outras pessoas tenham acesso. Nós, como pesquisadores, precisamos pensar na melhor forma de beneficiar a comunidade abrindo nossos dados e produtos para que estes sejam de fato utilizáveis por qualquer pessoa interessada. Somente assim, acreditamos que teremos uma comunidade pujante, onde não há muros e nem barreiras para a produção de pesquisas vanguarda. Como exemplo para a comunidade, o trabalho de Lyra \& Isotani (2017) disponibiliza todos os protocolos, ferramentas desenvolvidas, dados brutos, scripts estatísticos, e outros materiais (http://kamilalyra.github.io/Experimento-Infograficos/index.html), de forma 
aberta, para que todos possam reproduzir os resultados obtidos e dialogar com a comunidade sobre as evidências encontradas. Na mesma direção, o trabalho de Tenório et al. (2017) disponibiliza os dados brutos de dois experimentos realizados com um sistema tutor inteligente chamado MeuTutor, para que outros pesquisadores possam reproduzir os resultados encontrados e construir novas questões de pesquisa nesta temática.

\subsection{Princípio IX: Menos egocentrismo, mais altruísmo científico}

Talvez esse seja um dos desafios mais complexos que temos que abordar para termos uma informática na educação baseada em evidências. Por um lado, produzir evidências faz sentido quando se tem pesquisadores preocupados e comprometidos em considerar o trabalho de outros como importantes para a produção de novos conhecimentos científicos. Isto fica bastante claro nas revisões de artigos que recebemos dos eventos da CEIE, que são normalmente rasas (salvo algumas exceções), sem nenhum tipo de contribuição relevante e algumas chegam a ter apenas entre uma e duas linhas. Este tipo de atitude na revisão mostra uma total falta de respeito com quem escreveu o artigo e um completo descompromisso com a comunidade. As pessoas envolvidas querem compartilhá-las de maneira adequada. Por outro lado, isso é benéfico apenas quando a própria comunidade está interessada em trabalhar com estas evidências com o objetivo de apoiar e melhorar os trabalhos dos colegas e da própria comunidade (e não apenas o seu próprio trabalho).

Esse altruísmo científico é um dos maiores problemas que enfrentamos hoje. Dando um exemplo simples, mas muito concreto para o leitor: quando submetemos um artigo a um evento, receber uma resposta de aceitação/negação é o que menos deveria importar; o que é mais valioso são os comentários recebidos por especialistas da área que podem ajudar no aprimoramento do trabalho e direcionamento das pesquisas futuras. Contudo, você já reparou que em muitos eventos, em particular no Brasil, os comentários dos revisores possuem apenas um parágrafo ou poucos parágrafos sem muita profundidade na avaliação? Muitas vezes recebemos aquela resposta de negação de um artigo com uma simples frase como "o trabalho é muito ruim e mal escrito". Isso é um exemplo típico de falta de altruísmo científico. Ou seja, poucos gastam o seu tempo para ajudar a melhorar o trabalho dos outros analisando as evidências e métodos científicos utilizados. Isso, a longo prazo, faz com que a comunidade não prospere tanto quanto poderia. Além disso, contribui para que os pesquisadores mais seniores não tenham vontade de continuar participando da comunidade. Se queremos de fato crescer e fortalecer a área de Informática na Educação, é fundamental utilizar parte de nosso tempo para ajudar nossos colegas a melhorarem seus trabalhos, oferecendo comentários mais ricos, criando ferramentas de código aberto, produzindo evidências, criando programas de mentoria e, finalmente, citando e destacando os trabalhos de relevância da nossa comunidade.

Um exercício que pedimos ao leitor que chegou até aqui é: ao invés de pensarmos em quantos artigos iremos publicar, mudemos a linha de raciocínio e pensemos em quantas pessoas vamos impactar com nosso trabalho e como podemos coletar evidências para mostrar que nossas ideias têm valor social e científico. Essa mudança de pensamento trará como consequência pesquisas mais relevantes para sociedade e, também, para o desenvolvimento de uma comunidade sólida e unida em prol de um bem comum: a melhoria da educação brasileira.

\subsection{Princípio X: Menos nós, mais todos nós}

Da mesma forma que pensamos em propor uma carta aberta à comunidade, não faria sentindo simplesmente propormos um conjunto de princípios sem deixar aberto para que novas propostas de princípios ou melhorias dos atuais pudessem ser feitas. Afinal de contas, é impossível para dois pesquisadores em nível intermediário de suas carreiras pensarem em todos os princípios essenciais que devem conduzir a comunidade para a pesquisa de qualidade. Desta forma, este princípio tem o objetivo de abrir para você, pesquisador que se sentiu provocado e 
motivado a também pensar em novos princípios que possamos debater. No link http://www.icmc.usp.br/e/1421e, você pode colocar a sua opinião sobre o artigo, comentar os princípios e propor novos princípios. Após coletarmos estes princípios, pretendemos disponibilizar à comunidade e organizar encontros que possam ampliar a discussão pela pesquisa em Informática na Educação baseada em Evidências, ao mesmo tempo, queremos que tais encontros viabilizem o estabelecimento de novos caminhos para a pesquisa de qualidade no país.

\section{Referências}

Benassi, V. A., Overson, C. E., \& Hakala, C. M. (2014). Applying science of learning in education: Infusing psychological science into the curriculum. Society for the Teaching of Psychology. Disponível em: http://teachpsych.org/ebooks/asle2014/index.php [GS Search]

Blanchard, E. G. (2015). Socio-cultural imbalances in AIED research: Investigations, implications and opportunities. In International Journal of Artificial Intelligence in Education, 25(2), 204-228. doi: 10.1007/s40593-014-0027-7 [GS Search]

Blikstein, P. (2013a). Digital fabrication and 'making' in education: The democratization of invention. In J. Walter-Herrmann \& C. Büching (Eds.), FabLabs: Of Machines, Makers and Inventors. Bielefeld: Transcript Publishers, 4, 1-21. ISBN: 978-3-8376-2382-6. [GS Search]

Blikstein, P. (2013b). Multimodal Learning Analytics. Proceedings of the III Learning Analytics Knowledge Conference (LAK 2013), Leuven, Belgium. doi: $\underline{10.1145 / 2460296.2460316}$ [GS Search]

Fuks, H., Raposo, A. B., \& Gerosa, M. A. (2002). Engenharia de Groupware: desenvolvimento de aplicações colaborativas. In XXI Jornada de Atualização em Informática, Anais do XXII Congresso da Sociedade Brasileira de Computação (Vol. 2, pp. 89-128). ISBN 85-8844224-8 [GS Search]

Huth, E. J. (1986). Irresponsible authorship and wasteful publication. Annals of Internal Medicine, 104(2), 257-259. doi: 10.7326/0003-4819-104-2-257 [GS Search]

Isotani, S., \& Bittencourt, I. I. (2015). Dados Abertos Conectados: Em busca da Web do Conhecimento. Novatec Editora. doi: 10.13140/RG.2.1.4355.6329 [GS Search]

Jaques, P. A., Seffrin, H., Rubi, G., de Morais, F., Ghilardi, C., Bittencourt, I. I., \& Isotani, S. (2013). Rule-based expert systems to support step-by-step guidance in algebraic problem solving: The case of the tutor PAT2Math. Expert Systems with Applications, 40(14), 54565465. doi: 10.1016/j.eswa.2013.04.004 [GS Search]

Jaques, P. A., Siqueira, S., Bittencourt, I. I., \& Isotani, S. (2017). Qualidade da Pesquisa Científica Brasileira em Informática na Educação: Desafios e Perspectivas. Workshop de Desafios da Computação aplicada à Educação. Anais do Congresso da Sociedade Brasileira de Computação, p. 1-7. Disponível em: https://www.researchgate.net/publication/318888683

Jaques, P. A.; Pimentel, M.; Siqueira, S.; Bittencourt, I. I.. (Org.) Série de Livros Metodologia de Pesquisa em Informática na Educação. Porto Alegre: SBC, 2019. Disponível em: $<$ http://metodologia.ceie-br.org/>

Liao, C. H. (2010). How to improve research quality? Examining the impacts of collaboration intensity and member diversity in collaboration networks. Scientometrics, 86(3), 747-761. doi: 10.1007/s11192-010-0309-2 [GS Search] 
Lyra, K., \& Isotani, S. (2017). Impacto do uso de infográficos como materiais de aprendizagem e suas correlações com satisfação, estilos de aprendizagem e complexidade visual. In Anais dos Workshops do Congresso Brasileiro de Informática na Educação, p. 46-56. doi: 10.5753/cbie.wcbie.2017.46 [GS Search]

Magalhães, C. V., Santos, R. E., Da Silva, F. Q., \& Gomes, A. S. (2013). Caracterizando a pesquisa em informática na educação no Brasil: um mapeamento sistemático das publicações do SBIE. In Simpósio Brasileiro de Informática na Educação, p. 22 - 31. doi: 10.5753/CBIE.SBIE.2013.22 [GS Search]

Pasquali, L. (2017). Psicometria: teoria dos testes na psicologia e na educação. Editora Vozes Limitada. ISBN 978-85-326-5612-4 [GS Search]

Pimentel, M. (2018). Um Pesquisador em Computação em Busca de um Modo de Fazer Pensar Pesquisas em Informática na Educação. Revista Brasileira de Informática na Educação, 26(01), 51. doi: 10.5753/RBIE.2018.26.01.51 [GS Search]

Posada, J. E. G., Buchdid, S. B., \& Baranauskas, M. C. C. (2016). Informatics in education: what the works published in Brazil reveal. Brazilian Journal of Computers in Education, 24(1), 142. 10.5753/rbie.2016.24.1.142 [GS Search]

Pyrko, I., Dörfler, V., \& Eden, C. (2017). Thinking together: What makes Communities of Practice work?, Human Relations, 70(4), 389-409. doi: 10.1177/0018726716661040 [GS Search]

Tenório, T., Bittencourt, I. I., Isotani, S., Pedro, A., Ospina, P., \& Tenório, D. (2017). Dataset of two experiments of the application of gamified peer assessment model into online learning environment MeuTutor. Data in brief, 12, 433-437. 10.1016/j.dib.2017.04.032 [GS Search]

Valente, J. A., \& de Almeida, F. J. (1997). Visão analítica da informática na educação no Brasil: a questão da formação do professor. Revista Brasileira de Informática na Educação, 1(1), 45-60. 10.5753/rbie.1997.1.1.45-60 [GS Search]

Vicari, R. M., Flores, C. D., Silvestre, A. M., Seixas, L. J., Ladeira, M., \& Coelho, H. (2003). A multi-agent intelligent environment for medical knowledge. Artificial Intelligence in Medicine, 27(3), 335-366. 10.1016/S0933-3657(03)00009-5 [GS Search] 